\title{
Germanica
}

\section{Une littérature de nomades et de voyageurs}

Jean-Marie Maillefer

\section{(2) OpenEdition}

Journals

Édition électronique

URL : http://journals.openedition.org/germanica/2182

DOI : 10.4000/germanica.2182

ISSN : 2107-0784

Éditeur

Université de Lille

\section{Édition imprimée}

Date de publication : 31 décembre 2001

Pagination : 7-9

ISBN : 9782913857063

ISSN : 0984-2632

Référence électronique

Jean-Marie Maillefer, « Une littérature de nomades et de voyageurs », Germanica [En ligne], 29 | 2001, mis en ligne le 20 septembre 2013, consulté le 06 octobre 2020. URL : http://journals.openedition.org/ germanica/2182 ; DOI : https://doi.org/10.4000/germanica.2182

Ce document a été généré automatiquement le 6 octobre 2020.

(c) Tous droits réservés 


\title{
Une littérature de nomades et de voyageurs
}

\author{
Jean-Marie Maillefer
}

Le sagace Sterne a réparti en quatre groupes tous
les individus sans occupation définie qui quittent
leur domicile : ceux qui voyagent surtout pour
cause de défaillances physiques ou intellectuelles,
ou par nécessité impérieuse, ou pour n'importe
quelle raison, ou purement et simplement sans
aucune raison. En réalité, j'appartenais, au sens le
plus fort du mot, à ces quatre groupes.
Jens Baggesen, Le Labyrinthe.

Loin d'être un genre mineur, le récit de voyage, sous ses diverses formes, a constitué une des matrices de la pensée occidentale. De l'Odyssée au périple des Argonautes, de l'Enéide à la quête du Graal, de la Divine Comédie à Don Quichotte, il n'a cessé de se perpétuer jusqu'à nos jours et de nourrir notre imaginaire, tandis que la figure du voyageur, homo viator, reste emblématique de la littérature. Mais les écrivains ne sont pas des voyageurs comme les autres. Si elle manifeste le goût, irrésistiblement humain, pour l'inconnu et l'attrait de la découverte, la relation de voyage ne se résume pas à une collection de traits pittoresques et exotiques, ni à un catalogue didactique de faits géographiques, historiques et sociaux. Elle révèle les préoccupations subjectives et les réflexions du narrateur non seulement sur les terrae incognitae qui constituent son sujet d'observation, mais surtout sur lui-même et sur le monde dont il est issu. Le voyageur part à la rencontre de soi-même.

2 Héritier d'une longue tradition, le journal de voyage acquiert une esthétique littéraire propre à partir du XVIII e siècle, notamment avec les Romantiques, tout en participant à la structure narrative d'autres genres : littérature de divertissement ou moralisatrice, romans picaresques, utopies et critiques sociales, Bildungsroman. Sous ses avatars variés, le voyage remplit donc le plus souvent une fonction symbolique, initiatique. Il renvoie à une thématique de la métamorphose. Répondant à des pulsions profondes (la 
volonté de savoir, le désir d'échapper à la routine et aux contingences), le voyage se caractérise en effet par quelques constantes. L'acte du voyage est marqué par les gestes éternels du voyageur: le désir de l'Ailleurs, le départ, le passage, les épreuves, les rencontres et le retour. Car ce qui distingue l'écrivain-voyageur de l'exilé, c'est le retour. Le voyage n'est qu'un prétexte, le médium d'une quête spirituelle qui doit déboucher sur une re-naissance. On part pour savoir d'où l'on vient.

3 Pour les littératures des «petits » pays, l'importance de l'Ailleurs est d'autant plus primordiale. C'est encore plus vrai pour des nations situées à la périphérie, comme en Scandinavie, où les auteurs ont de tout temps été sollicités par l'appel du large et ont aspiré à se ressourcer en visitant les grands centres intellectuels. Rares sont en effet les écrivains scandinaves qui n'ont pas effectué de périples plus ou moins longs à l'étranger. Si, chez beaucoup d'entre eux, le voyage apparaît comme une initiation, il a aussi constitué une réponse au risque d'étouffement que faisaient courir des sociétés longtemps enclavées et étriquées. Les auteurs réputés les plus scandinaves ont tous connu des années de vagabondage ou des séjours prolongés hors de leur pays : Fredrika Bremer, Ibsen, Strindberg, Hamsun, Karen Blixen, Harry Martinson, Eyvind Johnson... pour ne citer que quelques-uns des plus grands. Sait-on qu'Andersen fut aussi un grand voyageur qui parcourut l'Europe en tous sens et intitula son autobiographie Reisebilder (Images de voyage).

$4 \quad$ Les Scandinaves se sont emparés depuis longtemps du motif du voyage. La Saga d'Éric le Rouge et la Saga des Groenlandais en fournissent des exemples médiévaux. Le Voyage de Niels Klim dans le monde souterrain de Ludvig Holberg n'a pas à rougir d'une comparaison avec les Voyages de Gulliver. Les Voyages de Linné et de ses épigones illustrent la fascination de l'âge préromantique pour l'étrangeté du monde. Le Labyrinthe de Jens Baggesen (1792) s'inscrit explicitement dans la lignée de Rousseau et du Voyage sentimental de Sterne. La littérature scandinave a, plus près de nous, enfanté deux des plus beaux personnages de voyageur: Peer Gynt et Nils Holgersson. La position périphérique de la Scandinavie fournit sans doute l'une des explications à cet irrésistible désir de voyager, mais le voyage apparaît aussi dans le Nord comme une source constante d'inspiration, comme un support privilégié du romanesque et de la fiction, comme prétexte aussi à un questionnement du monde et de la société.

$5 \mathrm{Au} \mathrm{xx}^{\mathrm{e}}$ siècle, le Nord demeure à plus d'un titre la terre des écrivains voyageurs et l'expérience du voyage y reste un élément fondamental dans l'acte d'écrire. Les Scandinaves se sont montrés éclectiques en la matière, ils n'ont pas eu de destination privilégiée : la fièvre des voyages et l'abolition des distances les ont entrânés sur les cinq continents, dans les postures les plus diverses du voyageur : flâneur au début du siècle, vagabond dans les années vingt, reporter dans les années soixante et soixantedix, cosmopolite toujours. Le voyage devient bien plus qu'un pèlerinage ou un témoignage, il ouvre littéralement de nouveaux horizons et est intimement lié à l'éclosion du modernisme, comme le montre par exemple le titre choisi pour la revue suédoise Karavan (1934-1935). Ce sont ces différentes facettes que les contributions réunies ici voudraient illustrer. La fin actuelle des occasions d'explorations et d'aventures - et les désillusions qu'elle engendre - n'a pas eu pour corollaire l'obsolence de la relation de voyage, mais un renouvellement et une réappropriation du genre sur le mode du symbolique et du fantastique, marqué par le désenchantement et la redécouverte de sa dimension métaphysique. Ainsi le voyage continue-t-il à matérialiser une forme, propre au Nord, de « la dialectique du désir ». 